\title{
Identification of Two Meloidogyne hapla Genes and an Investigation of Their Roles in the Plant-Nematode Interaction
}

\author{
Cynthia Gleason, ${ }^{1,2,4}$ Frederik Polzin, ${ }^{1}$ Samer S. Habash, ${ }^{3}$ Lei Zhang, ${ }^{4}$ Jan Utermark, ${ }^{1}$ \\ Florian M. W. Grundler, ${ }^{3}$ and Abdelnaser Elashry ${ }^{3}$
}

${ }^{1}$ Georg August University, Albrecht von Haller Institute for Plant Sciences, Dept. of Molecular Biology and Physiology of Plants, Julia-Lermontowa-Weg 3, 37077 Göttingen, Germany; ${ }^{2}$ Georg August University, Göttingen Center for Molecular Biosciences (GZMB), Dept. of Molecular Biology and Physiology of Plants, Julia-Lermontowa-Weg 3, 37077 Göttingen, Germany; ${ }^{3}$ University of Bonn, INRES Molecular Phytomedicine, Karlrobert-Kreiten str. 13, 53115 Bonn, Germany and Agricultural Research Centre, Agricultural Genetic Engineering Research Institute, 9 Gamaa st., Giza 12619, Egypt; and ${ }^{4}$ Washington State University, Plant Pathology Department, Pullman, WA 99164 U.S.A.

Accepted 20 December 2016.

\begin{abstract}
Root-knot nematodes are soil-borne pathogens that invade and establish feeding sites in plant roots. They have an extremely broad host range, including most vascular plants. During infection of a susceptible host, root-knot nematodes secrete molecules called effectors that help them establish an intimate interaction with the plant and, at the same time, allow them to evade or suppress plant immune responses. Despite the fact that Meloidogyne hapla is a significant pest on several food crops, no effectors have been characterized from this root-knot nematode species thus far. Using the published genome and proteome from M. hapla, we have identified and characterized two genes, MhTTL2 and $M h 265$. MhTTL2 encodes a predicted secreted protein containing a transthyretin-like protein domain. The expression of MhTTL2 was up-regulated during parasitic life stages of the nematode, and in situ hybridization showed that MhTTL2 was expressed in the amphids, suggesting it has a role in the nematode nervous system during parasitism. We also studied the gene Mh265. The Mh265 transcript was localized to the subventral esophageal glands. An upregulation in Mh265 expression coincided with the pre- and early-parasitic life stages of the nematode. When Mh265 was constitutively expressed in plants, it enhanced their susceptibility to nematodes. These transgenic plants were also compromised in flg22-induced callose deposition, suggesting the Mh265 is modulating plant basal immune responses.
\end{abstract}

Root-knot nematodes are obligate biotrophs that have a huge host range of more than 5,000 plant species, including most important crop plants, and infection can lead to billions of dollars in global yield losses each year (Chitwood 2003; Sasser and Freckman 1987). Many front-line nematicides have been banned or withdrawn from the market, due to their toxicity to nontarget organisms and their harmfulness to the environment (Fuller et al. 2008). To meet food security needs, there is pressure to develop

Corresponding author: C. Gleason; E-mail: cynthia.gleason@wsu.edu

*The $\boldsymbol{e}$-Xtra logo stands for "electronic extra" and indicates that ten supplementary figures and one supplementary table are published online.

This article is in the public domain and not copyrightable. It may be freely reprinted with customary crediting of the source. The American Phytopathological Society, 2017. novel, environmentally friendly nematode resistance strategies, and this will require an understanding of the complex interaction between nematodes and host plants at a molecular level.

Upon root invasion, the second-stage juveniles (J2) migrate toward the vascular cylinder. They perforate the cell walls of two to ten cells with their stylets and secrete a mixture of proteins with a mostly unknown composition. The affected plant cells redifferentiate into multinucleate, highly metabolically active feeding structures called giant cells (de Almeida Engler and Gheysen 2013). The feeding cells provide the nematode with sustenance as it completes its life cycle (Caillaud et al. 2008). The nematode will molt three more times, until it finally reaches the adult stage that, in the case of the female, will lay its eggs at the surface of the root. The cortical cells that surround the giant cells and developing nematode undergo hypertrophy and hyperplasia, resulting in root swellings called galls (Rodiuc et al. 2014). Root galling is a typical phenotype of root-knot nematode infection. The presence of root-knot nematodes in the root vasculature depletes the plant of organic nutrients and interferes with plant water and inorganic nutrient transport toward the shoot. As a result, infected plants exhibit reduced growth and yield (Abad et al. 2003).

One of the first lines of plant defense against pathogens involves the recognition of conserved pathogen molecules, referred to as pathogen-associated molecular patterns (PAMPs). PAMPs can be recognized by surface-localized pattern recognition receptors (Monaghan and Zipfel 2012; Zipfel 2014). Recognition of the PAMP elicits a defense response called PAMPtriggered immunity (PTI), which includes production of reactive oxygen species (ROS), activation of mitogen-activated protein (MAP) kinases, increased expression of defense genes, and callose deposition (Dodds and Rathjen 2010; Senthil-Kumar and Mysore 2013; Wu and Zhou 2013). The process of root penetration, invasion, and feeding-site formation and maintenance by nematodes may activate PTI (Goverse and Smant 2014). In fact, it was recently shown that a conserved nematode molecule called ascaroside 18 (Ascr\#18) is recognized by the plant, triggering defense-gene expression. In addition, plants treated with Ascr\#18 exhibited enhanced resistance to diverse pathogens, suggesting that this conserved molecule is activating innate immunity (Manosalva et al. 2015). Additional evidence that PTI plays a role in plant-nematode interactions comes from work on Arabidopsis treated with flg22, a component of the bacterial flagellum. The flg22 treatment not only induced canonical PTI responses 
in the plants but, also, enhanced their resistance to nematodes (Teixeira et al. 2016).

To successfully overcome PTI, the nematode is likely secreting effectors that can suppress plant immune responses. Recently, several PTI-suppressing effectors from phytoparasitic nematodes have been identified and characterized. For example, the $M$. incognita calreticulin (Mi-CRT) effector is secreted from the nematode esophageal glands and is injected into the plant apoplast, in which it suppresses basal plant immunity (Jaouannet et al. 2013). Arabidopsis plants that stably express the secreted form of Mi-CRT were more susceptible to nematodes and, after treatment with the PAMP elf18, the transgenic plants had suppressed induction of PTI-marker genes and reduced levels of callose deposition (Jaouannet et al. 2013). Similarly, potato cyst nematodes (Globodera rostochiensis) secrete an effector called GrCEP12 during potato infections, and plants that express GrCEP12 showed reduced PTI-marker gene expression after flg22 treatment, indicating that GrCEP12 also has PTI-suppressing activity (Chen et al. 2013). In the last few years, there has been an increasing number of PTI-suppressing effectors identified from plant-parasitic nematodes, but their modes of action are largely unknown. Expression of the individual effectors tends to have modest effects on plant susceptibility, so it is likely that the concerted action of multiple effectors reduces PTI. Root-knot nematodes secrete a large repertoire of proteins from their stylets and other secretory organs and, for a majority, their functions, including their possible roles in parasitism, are still a mystery (Haegeman et al. 2012; Rehman et al. 2016).

Meloidogyne hapla is often referred to as the northern rootknot nematode because it is usually found in temperate climates and can cause significant damage on crops such as carrots, potatoes, lettuce, and strawberries. The M. hapla genome has been fully sequenced and, interestingly, it is significantly smaller in size $(54 \mathrm{Mb})$ than the genome of its relative Meloidogyne incognita (86 Mb) (Abad et al. 2008; Opperman et al. 2008). Because of our interest in nematode effectors that can affect plant defense, we searched M. hapla for effectors. For this search, we used the proteome and genome information of M. hapla. We looked for two types of genes: i) genes that encode proteins with unknown function and only present in root-knot nematodes and ii) genes that encode proteins with domains that have been previously associated with either effectors, parasitism, or both. Genes that met at least one of these criteria and that were transcriptionally up-regulated during one or more nematode life stage associated with parasitism were further studied. Here, we show the first results from our efforts and describe two new genes from M. hapla. The first is MhTTL2, which is expressed in the nematode amphids and whose expression is up-regulated during parasitic life stages. The second gene of interest is $M h 265$, which encodes a novel protein. The Mh265 transcript is localized to the esophageal glands. When Mh265 was expressed by a bacterial pathogen, it enhanced bacterial growth in planta, suggesting it may have a role in plant defense modulation. Plants expressing Mh265 were more susceptible to both root-knot and cyst nematode infection. Interestingly, the plants exhibited a reduction in PAMPinduced callose deposition, linking the suppression of callose deposition to nematode susceptibility. Through the study of MhTTL2 and $M h 265$, we have gained further insights into root-knot nematode genes that encode secreted proteins and, for Mh265, we propose that it has a role in suppressing plant basal immunity.

\section{RESULTS}

\section{Effector candidates are expressed during parasitic stages} of the nematode in secretory organs.

In order to identify new nematode effector candidates in the model root-knot nematode, we have focused on two novel genes, called Mh265 and Mh270 (later called MhTTL2). These proteins were originally identified as peptides from the $M$. hapla proteome (Mbeunkui et al. 2010).

The $M h 270$ candidate caught our attention because the published peptide sequence was annotated as a transthyretin-like (TTL) protein precursor (Mbeunkui et al. 2010). TTL proteins are a diverse group of nematode-specific proteins that contain the canonical TTL domain (DUF290, PF01060). For a majority of TTLs, their functions are unknown (Jacob et al. 2007). The second gene of interest was called Mh265. Using the published peptide information (Mbeunkui et al. 2010), we could find the coding sequence for $M h 270$ and Mh265 from the M. hapla genome sequence and design gene-specific primers for transcript analysis and in situ hybridization (Supplementary Figs. 1 and 2; Supplementary Table 1).

Because genes involved in pathogenicity may be upregulated during the parasitic life stages of the nematode, real-time reverse transcription polymerase chain reaction (qRT-PCR) was performed to measure gene expression of Mh265 and Mh270 in egg, $\mathrm{J} 2$, and in parasitic nematodes. For the parasitic nematodes, root tissue from infected Arabidopsis Col-0 plants at 6 and 14 days postinoculation (dpi) was collected. Acid fuchsin staining of the nematodes in the roots revealed that, at $6 \mathrm{dpi}$, the $\mathrm{J} 2$ were still migrating in the roots. At $14 \mathrm{dpi}$, a majority of the nematodes were in the J3 or J4 stage (Supplementary Fig. 3). For the qRTPCR analysis, the transcript levels were normalized to the geometric mean of the expression of the reference genes $M h 18 S$ and MhActin. Transcriptional analysis showed that there was enhanced gene expression for Mh265 and Mh270 in preparasitic J2 and in parasitic J2 (6 dpi) life stages, as compared with expression in the egg stage. At $14 \mathrm{dpi}$, the gene expression for both Mh265 and Mh270 was similar to that of the egg stage (Fig. 1). These results showed that relative expression of Mh265 and $M h 270$ is highest during the key early phases of nematode-plant interaction, suggesting that Mh265 and Mh270 are involved in, one or both, root invasion and the formation of the feeding sites.

To determine the specific localization of Mh265 and Mh270 transcripts in the nematode, we performed in situ hybridization using digoxigenin (DIG)-labeled single strand DNA probes for both candidate effector genes. The $M h 270$ probe showed light staining on paired structures in the nematode head, similar to the localization of the amphidal effector MAP-1 (Vieira et al. 2011). The probe signal was anterior of the metacorpus, consistent with the position of the nematode amphids (Fig. 2). The staining pattern of the $M h 265$ probe was similar to the staining pattern of the probe for the polygalacturonase gene Mi-pg-1 (Fig. 2), which specifically labels the subventral glands (Jaubert et al. 2002). Thus, the Mh265 transcript localized to esophageal glands, specifically the subventral glands of the preparasitic J2 (Fig. 2). At the same time, the sense probes for Mh265, Mh270, and $M i-p g-1$ did not show nonspecific hybridization to the $\mathrm{J} 2$.

\section{Identification of Mh270 and Mh265 sequence from M. hapla.}

Based on the peptide sequence of $M h 270$, we identified the corresponding gene from the $M$. hapla genome at scaffold MhA1_Contig277: 78,674 to 79,346. This region has a coding sequence that is $465 \mathrm{bp}$ in size and that is predicted to undergo alternative splicing, producing a 426-bp coding sequence. These predicted transcripts encode a 154- and a 141-amino acid (aa) proteins, respectively, and they contain a TTL family domain (PF01060) (Fig. 3). A BLASTp search of the nonredundant database, using the 154- and 141-aa sequences, showed similarity to Meloidogyne javanica TTL2 (88 and 87\% aa identity, respectively) and the lesion nematode Radopholus similis TTL2 precursor (87 and $86 \%$ aa identity, respectively) (Fig. 3). Because of the similarity to TTL2 proteins, we refer to the gene corresponding to $M h 270$ as MhTTL2. 
There is a single gene encoding MhTTL2 in the M. hapla genome, and this is predicted to encode a 465-bp transcript and a 426-bp alternatively spliced transcript. However, when we tried to amplify the MhTTL2 coding region from J2 cDNA, we could only amplify the 426-bp isoform. To determine if the 465-bp transcript was present in the $\mathrm{J} 2$, we created primers that could distinguish between the 465- and the 426-bp isoforms of the cDNA and found only the 426-bp transcript in the cDNA from all life stages tested (eggs, J2, and nematodes at 6 dpi). We then aligned the 154- and 141-aa sequences to the TTL2 homologs in other nematode species and found that the longer predicted isoform (154-aa protein) contains 13 aa that are not found in any of the other TTL2 protein sequences (Fig. 3). Because gene structure is often conserved between orthologous genes and because we were not able to empirically verify the presence of the longer predicted transcript, we refer to the 426bp isoform as MhTTL2 in this paper.

When this MhTTL2 predicted protein sequence (141 aa) was fed into SignalP 4.1 and transmembrane hidden Markov model (TMHMM) algorithms, they were predicted to contain a secretion signal peptide with a cleavage site between positions 26 (alanine) and 27 (glutamic acid) (Fig. 3), and no predicted transmembrane domains beyond that cleavage site. The presence of a secretion peptide and the lack of transmembrane domains are two indications that the protein is secreted via the nematode secretory system, and it may ultimately be secreted from the nematode and enter the plant. This points to a function outside the nematode. Because we wanted to express nematode genes in a prokaryotic expression system, we ensured that MhTTL2 protein had no predicted eukaryotic glycosylation sites (GlycoEP) or N-terminal acetylation sites (NetAcet 1.0), which are common posttranslational modifications.

In the sequenced sedentary plant parasitic nematodes, there are two MhTTL2 homologs in Meloidogyne incognita (94\% aa identity to MhTTL2), one MhTTL2 homolog in Meloidogyne floridensis (partial coding sequence encoding protein with $98 \%$ aa identity to MhTTL2), and one MhTTL2 homolog in Globodera pallida (encoding protein with $70 \%$ aa identity to MhTTL2) (Fig. 3). In addition, MhTTL2 has a degree of amino acid sequence identity to the TTL family proteins from animal
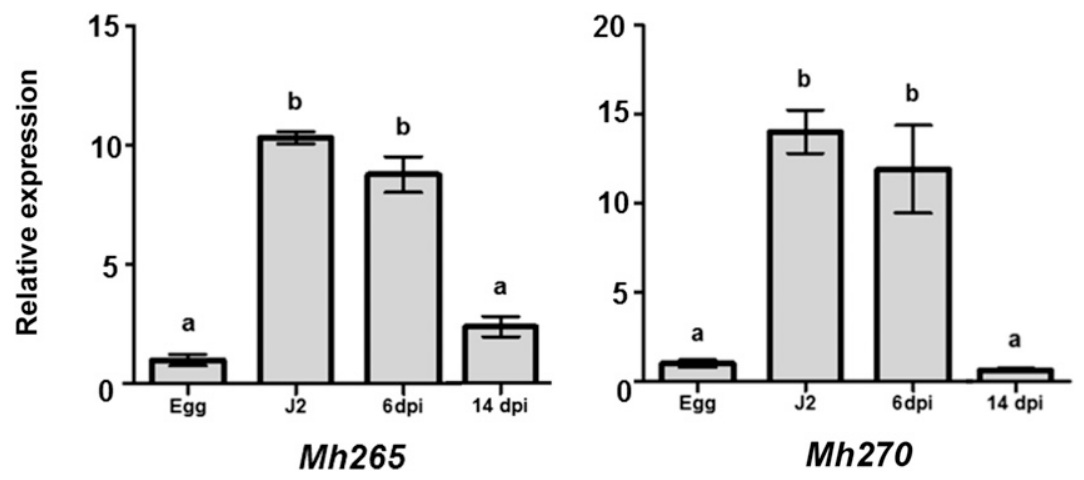

Fig. 1. Expression analysis of $M h 265$ and $M h 270$ shows that both are transcriptionally up-regulated during pre- and early-parasitic life stages. The relative transcript abundance for Mh265 and Mh270 was determined for Meloidogyne hapla eggs and preparasitic J2 and for M. hapla in Arabidopsis roots at 6 and 14 days postinoculation (dpi). The transcripts were normalized using the geometric mean of the expression levels of two endogenous reference genes, Mh18S and MhActin. Each reaction was done in triplicate on two independent biological replicates. The bars represent the arithmetic mean of the replicates \pm standard error of the mean. Expression in egg stage was set to 1 . Letters indicate a significant difference between groups, using one-way analysis of variance $(P<0.05)$. $\mathrm{J} 2=$ preparasitic stage 2 juvenile.


Fig. 2. In situ hybridization reveals that $M h 270$ is expressed in the amphids and Mh265 in the subventral glands in second-stage juveniles. The in situ hybridization antisense probe for $M h 270$ hybridized to two structures that lie anterior to the metacorpus. For $M h 265$, the probe hybridized to the esophageal gland. Two representative photos are shown for Mh270 and Mh265 antisense probes. The Mi-pg-1 probe hybridized to the subventral esophageal glands. The sense probes for Mh270, Mh265, and Mi-pg-1 did not give any detectable signals. 
parasites, such as Brugia malayi (46\%) and Wuchereria bancrofti (49\%), Loa loa (47\%), and Toxocara canis (46\%) (Supplementary Figs. 4 and 5).

Mh265 is a gene with an 801-bp open reading frame that encodes a 266-aa protein. In silico analyses showed that Mh265 contained a signal peptide (SignalP 4.1) with a predicted cleavage site between position 24 (serine) and position 25 (glutamine) (Fig. 4). Moreover, using the TMHMM algorithm, Mh265 was predicted to lack transmembrane domains. Mh265 also had no predicted eukaryotic glycosylation sites or N-terminal acetylation sites. A tBLASTn search of the M. hapla genome using Mh265 protein sequence resulted in a single hit on contig MhA1_Contig2749 (e Val = 3.5E-135), indicating that it is a single gene in the M. hapla genome. There are predicted $M h 265$ homologs in $M$. incognita (59\% aa identity) and $M$. floridensis (56\% aa identity) (Fig. 4). A BLAST search for Mh265 protein homologs in cyst nematodes (Globodera pallida, Heterodera schachtii, Heterodera avenae) and other plant parasitic nematodes (Pratylenchus coffeae and Hirschmanniella oryzae) found proteins with limited homology to Mh265 (30 to 39\% aa identity) (Supplementary Figs. 6 and 7). Based on this data, Mh265 is likely to be specific to root-knot nematodes.

\section{Expression of Mh265 in Arabidopsis enhances plant susceptibility to plant parasitic nematodes, but MhTTL2 does not.}

We wanted to look at the effect of cytoplasmic expression of the transgenes on plant susceptibility, since previous works have shown that many nematode effectors are targeted to the plant cell cytoplasm. First, to study the subcellular localizations of Mh265 and MhTTL2 (minus signal peptide sequences [-sp]) in planta, we transiently expressed the proteins in tobacco leaf epidermal cells. In order to prevent them from passively diffusing into the nucleus since the two proteins have low molecular weights (Grebenok et al. 1997), Mh265 and MhTTL2 (-sp) were fused to the enhanced green fluorescent protein (eGFP) and $\beta$-glucuronidase (GUS), using pGUS-ENTR vectors (Zhang et al. 2015). Confocal microscopy imaging showed that the cells expressing free GFP (not fused to GUS) had fluorescence in the cytoplasm and nuclei. Both Mh265 and MhTTL2 were located in the cytoplasm of agroinfiltrated tobacco leaf cells, as indicated by the intracellular staining of the cytoplasmic strands. The fluorescently tagged effectors were not found in the nuclei (Fig. 5).

In order to test if the effector candidates have roles in modulating plant susceptibility, Mh265 and MhTTL2 were cloned without their predicted signal peptide sequences and were expressed untagged in Arabidopsis Col-0 under the control of the constitutive Cauliflower mosaic virus $35 \mathrm{~S}$ promoter. Transgene expression in independent lines was confirmed by qRT-PCR, and no obvious growth phenotypes, such as altered root length, were observed in either the $35 S:: M h 265$ or $35 S:$ : MhTTL2 transgenic lines (Supplementary Figs. 8, 9, and 10).

Two independent, homozygous T3 lines expressing 35S:: Mh265 were used in nematode infection assays with M. hapla. At 4 weeks postinoculation, the relative amount of galling was measured in comparison with the two controls, i.e., Col-0 and a

\section{Signal peptide}

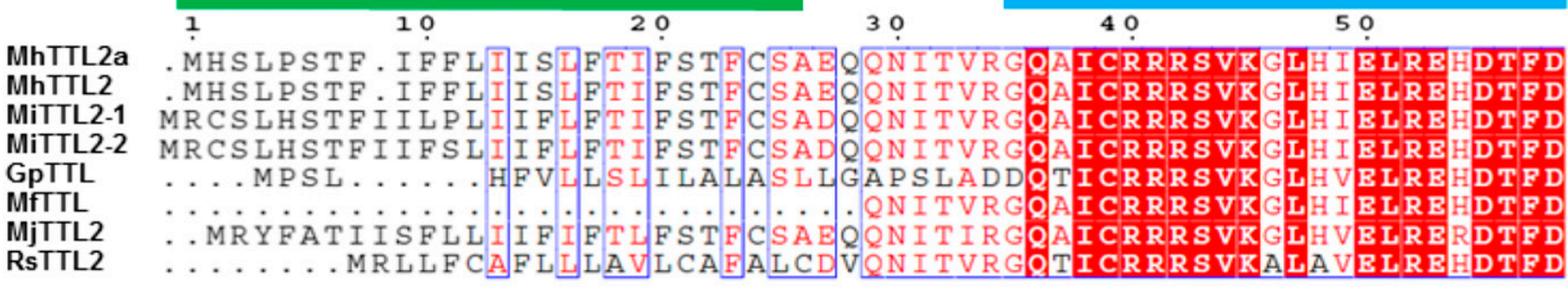

Pfam01060 domain

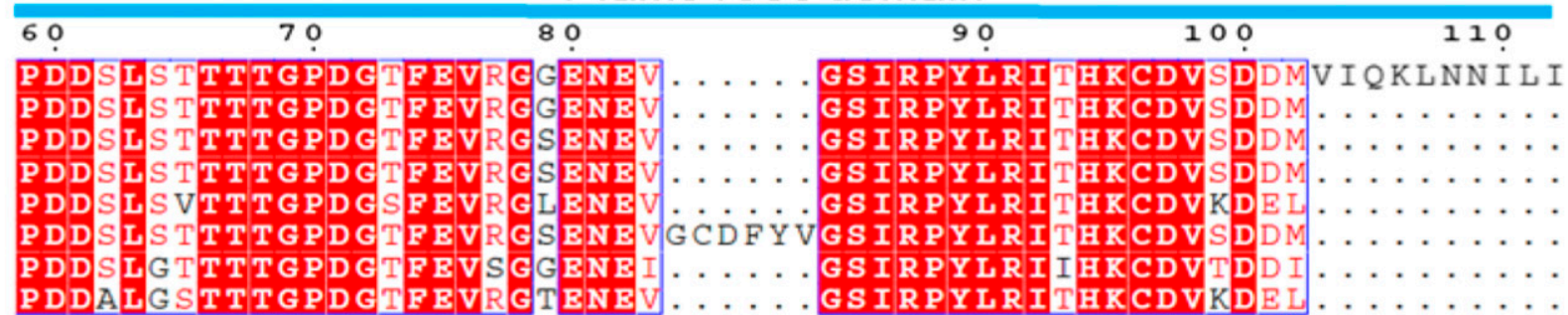

MhTTL2a
MHTTL2
MiTTL2-1
MiTTL2-2
GPTTL
MFTTL
MjTTL2
RsTTL2

\begin{tabular}{|c|c|c|}
\hline & 130 & 140 \\
\hline hTTL2a & RQTEIDIPKEKVN & FVN LN LPGHRDKETCDD \\
\hline TTL2 & Q̈TEIDI PKEKVN & G I Y EMN F VN L N L P G H R D K T C D D \\
\hline MiTTL2-1 & KCRRITEIDI PKEKVN & G I Y EMN F VN LN L P G H R K K T CD D \\
\hline MiTTL2-2 & KCRRITEIDI PKEKVN & . G I YEMNFVNLNL PGHRD/KETCDD \\
\hline GpTTL & RV S E & NGVYEMNFVNLNVHGHRDTESCEE \\
\hline MfTTL & . & $\dot{-}$ \\
\hline MjTTL2 & RTT E I D I Q KD KVN & . G I Y EMNFVNLNL P G H R D NENCD D \\
\hline STTL2 & $\ldots$ KCRRVTEIDI PKDKVN & HG VY EMNF I N S NV P GHRDTET CD \\
\hline
\end{tabular}

Fig. 3. Multiple sequence alignment of the two predicted proteins MhTT2a (154 aminco acids [aa]) and MhTTL2 (141 aa) with TTL2 homologs from other nematode species. The TTL2 homologs are from Meloidogyne incognita (MiTTL2.1, transcript ID Minc02278, and MiTTL2.2, transcript ID Minc04433), Globodera pallida (transcript ID GPLIN_000273800), M. floridensis (transcript ID maker-nMf.1.1.scaf41846-augustus-gene-0.3), M. javanica (AKV89654.1, transthyretin-like (TTL) protein 2), and Radopholus similis (CAM84511.1, TTL protein 2 precursor). The predicted signal peptide (aa 1 to 26) is indicated with a green bar and the conserved DUF290 (pfam01060) domain is indicated with a blue bar. Strictly conserved residues are in white type on a red background; well-conserved residues are in red type, and conserved regions of residues are in blue boxes. 
stable transgenic line of Col-0 transformed with $35 S:: G F P$. Galling is an easy-to-score phenotype and indicates that the nematode has successfully entered the root and established a feeding site. There was no significant difference in $M$. hapla galling between the Col-0 and the $35 S:: G F P$ line (GFP), but plants from the two lines expressing $35 S:: M h 265$ showed enhanced galling (Fig. 6A). We next investigated if the expression of Mh265 in Arabidopsis could enhance susceptibility to the cyst nematode Heterodera schachtii. The $35 S:: M h 265$ plants had more female nematodes present within roots at $14 \mathrm{dpi}$, compared with wild type (Col-0) (Fig. 6B).

Next MhTTL2 transgenic lines were tested with M. hapla to determine if they have altered nematode susceptibility to the nematode. Two transgenic lines expressing the 426-bp coding sequence (minus the secretion signal sequence) under the control of the $35 \mathrm{~S}$ promoter were inoculated with $M$. hapla juveniles. At 4 weeks postinoculation, there was no significant difference in the galling between the $35 S: \because M h T T L 2$ transgenic lines and the control, indicating that MhTTL2 expression in the cytoplasm has no effect on nematode susceptibility (Fig. 6C).

\section{Plants expressing Mh265 show reduced} flg22-induced callose deposition.

Callose deposition is a hallmark of the PTI response (Ellinger and Voigt 2014; Luna et al. 2011). There is evidence that

\section{Signal peptide}



\begin{tabular}{|c|c|c|c|c|c|}
\hline & 60 & 90 & 100 & & 110 \\
\hline h26 & DD & EDGFAGIKKWMES IDTEKVGQF I QNFA & PAKL ST & & \\
\hline & 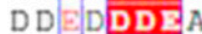 & KLMESID & PAKL & KFQDY & P BसW \\
\hline
\end{tabular}

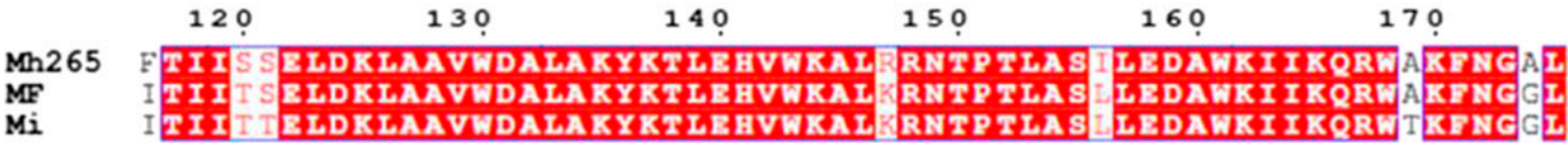

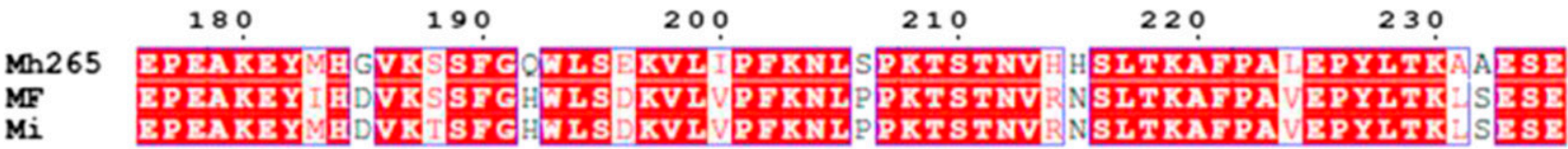



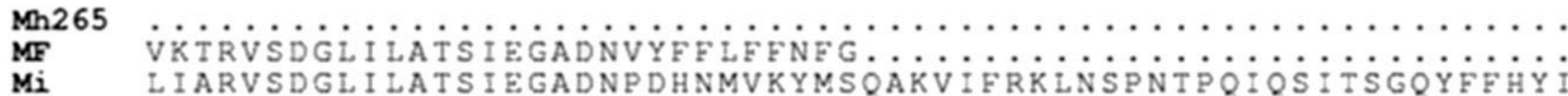

$\operatorname{Mh} 265$

Mi

$\operatorname{Mn} 265$

MF

Mi

Mh2 265
MF
Mi

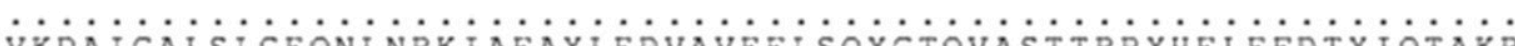

VKDAICALSLCEONLNRKIAFAYLEDVAVEFLSOYGTOVASTTRPYHFLEFDTYIOTAKR

Fig. 4. Multiple sequence alignment of Mh265 with the closest BLAST hits from other nematode species. Mh265 protein sequence is aligned with its closest homologs in Meloidogyne floridensis (Mf, transcript ID scaffold nMf.1.1.scaf01985: 61-1,938), and M. incognita (Mi, transcript ID Minc17234). The signal peptide (amino acids 1 to 24) is designated with a green bar. Strictly conserved residues are in white type on a red background; well-conserved residues are in red type, and conserved regions of residues are in blue boxes. 
callose deposition is elicited in response to nematode infection, and the callose deposits may play a role in basal resistance against plant-parasitic nematodes (Holbein et al. 2016). The enhanced susceptibility of Mh265 transgenic plants against two major groups of plant-parasitic nematodes suggested that Mh265 may be modulating components of PTI. Therefore, we investigated whether Mh265 protein affected PAMPtriggered callose deposition. As expected, infiltration with flg22 induced callose deposition in the leaves of the control plants (Col-0 and 35S::GFP). However, after flg22 treatment, the leaves from both $35 S:: M h 265$ transgenic lines had significantly fewer callose deposits (Fig. 7A and B). Our results suggest that flg22-triggered callose response in Arabidopsis seedlings is suppressed by the presence of Mh265.

Because 35S::Mh265 plants are affected in a component of PTI, we questioned whether these transgenic plants were also affected in susceptibility to Pseudomonas syringae pv. tomato DC3000. We infiltrated the leaves of 4-week-old Col-0 and $35 S:: M h 265$ lines with $P$. syringae pv. tomato DC3000. At 3 dpi, the bacterial growth was similar between $35 S:: M h 265$ transgenic lines and Col-0 (Fig. 7C).

\section{Heterologous expression of $M h 265$ \\ in Pseudomonas syringae leads}

to enhanced bacterial growth in planta.

Thus far, it is impossible to generate transformants of plantparasitic nematodes to express transgenes. To still determine whether ectopic, heterologous expression of Mh265 in a pathogen itself would enhance its virulence, we used the bacterial pathogen $P$. syringae pv. tomato DC3000 as a surrogate system to administer Mh265 into the plant cytoplasm. Although P. syringae pv. tomato DC3000 does not have a stylet, it can deliver effectors into the plant cell via its type III secretion apparatus. The coding sequence for $M h 265$ (-sp) was introduced into the effector detector vector (EDV), which was designed to fuse effectors to a type III secretion signal so that bacteria can deliver them into the plant cells (Fabro et al. 2011; Sohn et al. 2007). The in-frame construct was introduced into the $P$. syringae pv. tomato DC3000 expressing the luciferase (luxCDABE) operon of Photorhabdus luminescens (Pst-LUX). The luciferase reporter allows the estimation of bacterial abundance by measuring the bacterial bioluminescence. Successful bacterial transformation was confirmed by colony PCR, and no influence on bacterial growth on rich growth media could be observed due to the presence of the transgene (data not shown). Pst-LUX expressing either pEDV6-Mh265, pEDV6-ATR13 ${ }^{\text {Emco5 }}$, or pEDV6-YFP (control) were spray-inoculated onto Col- 0 plants and the relative bioluminescence (light units to fresh weight) was measured at $3 \mathrm{dpi}$. The effector ATR $13^{\text {Emco5 }}$ from Hyaloperenospora arabidopsidis had previously been shown to increase bacterial growth on the plants using this system (Fabro et al. 2011). Both pEDV6-Mh265 and the positive control pEDV6-ATR13 ${ }^{\text {Emcos }}$ significantly increased bacterial growth in planta compared with pEDV6-YFP (Fig. 8).

\section{DISCUSSION}

Here, we have identified and characterized two new nematode genes, Mh265 and MhTTL2, from the northern root-knot nematode $M$. hapla. The protein MhTTL2 drew our interest because it contains a TTL domain. The TTL genes belong to a nematodespecific gene family that was originally identified in C. elegans and have subsequently been identified in animal and plant parasitic nematodes, including root-knot nematodes $(M$. incognita and $M$. javanica), cyst nematodes (Globodera pallida and Heterodera glycines), and lesion nematodes (Xiphinema index and Radopholus similis) (Furlanetto et al. 2005; Gao et al. 2003; Jacob et al. 2007; Lin et al. 2016; Saverwyns et al. 2008; Sonnhammer and Durbin 1997). MhTTL2 is the first TTL gene characterized from $M$. hapla.

TTL genes are part of a large gene family, and their function in nematodes is not clear. In C. elegans, silencing of five individual TTL genes did not result in any phenotype, perhaps due to functional redundancy (Saverwyns et al. 2008). Expressed sequence tag mining for TTL proteins has shown that although TTL proteins are found in free-living nematodes, they are more common in parasitic nematodes, especially in the parasitic life stages (Saverwyns et al. 2008). In animal parasitic nematodes, TTLs have been found in the excretory-secretory products, which suggests they are secreted and have a role in the hostnematode interaction (Hewitson et al. 2008; Saverwyns et al. 2008). Recently, TTL5 was found to be secreted from the rootknot nematode $M$. javanica and was shown to have a role in plant parasitism (Lin et al. 2016). When MjTTL5 is expressed in plants, it can interact with the Arabidopsis ferredoxin:thioredoxin reductase catalytic subunit. This interaction promotes ROS scavenging activity in the plant and, as a result, modulates the plant immune reaction to promote nematode infections (Lin et al. 2016). While this data provides tantalizing evidence that TTLs may encode nematode effectors, phylogenetic analysis places MjTTL5 far from the monophyletic group containing the other MjTTLs, namely, MjTTL2, MjTTL1, MjTTL3, and this suggests that MjTTL5 may have a unique function in plant parasitism (Lin et al. 2016).

To determine if MhTTL2 protein plays a role in parasitism, plants were transformed to express MhTTL2 (-sp). We had worked under the assumption that plant-parasitic nematode effectors are often delivered to the plant cell cytoplasm. However, the transgenic plants were not altered in their nematode susceptibility and, as a result, we were unable to link MhTTL2 with a function in parasitism.


Fig. 5. Transient expression of Mh265 and MhTTL2 fluorescent fusion proteins shows that they localize to the plant cytoplasm. The subcellular compartments targeted by A, enhanced green fluorescent protein (eGFP), B, Mh265 fused to eGFP and $\beta$-glucuronidase (eGFP-GUS-Mh265), and C, MhTTL2 fused to eGFP and $\beta$-glucuronidase (eGFP-GUS-MhTTL2) were determined by confocal imaging. Scale bar, $50 \mu \mathrm{m}$. 
It is possible that MhTTL2 functions outside the plant cytoplasm, which may explain why we did not see a phenotype in our transgenic lines. Some root-knot nematode effectors localize and function outside the plant cells (Vieira et al. 2011). For example, Mi-CRT is secreted by the nematode into the apoplast, in which it acts to suppress plant immunity (Jaouannet et al. 2013). Mi-CRT is made in the subventral glands of the nematode and is secreted through the stylet to the cell walls of the giant cell (Jaouannet et al. 2013). We show that MhTTL2 transcript localized to the amphids. Since the amphids serve as chemosensory sensilla (sense organs) (Perry 1996) and are open to the environment, amphid secretions can be released by the nematode into the extracellular space during infection. Therefore, it is possible that MhTTL2 is secreted from the amphid into the apoplast.

MhTTL2 would not be the first root-knot effector identified that was, one or both, produced in or secreted from the amphids. Recent work has identified secreted nematode effectors that are expressed either in the amphids or in the cells associated with the amphids (Mitchum et al. 2013). For example, in Globodera pallida, a novel group of hypervariable extracellular (HYP) effectors are produced in cells near the amphids and these effectors are localized to plant apoplast during infection. Silencing HYP effectors reduced the number of nematodes that could successfully infect the plant (Eves-van den Akker et al. 2014). In rootknot nematodes, the putative avirulence factor MAP-1 was shown to be secreted from the amphids and to accumulate in the plant apoplast (Vieira et al. 2011), in which it may play a role in effector-triggered immunity (Semblat et al. 2001).

Interestingly, MhTTL2 is similar to RsTTL2, which is expressed in the nerve chords, and, because of this location, it is hypothesized that RsTTL2 and other related TTLs may have some function related to the nervous system (Jacob et al. 2007). Although we did not detect the MhTTL2 probe signal in the nerve chords, its localization in the amphids, which are part of the nervous system, suggests that MhTTL2 may function in the nervous system and is possibly secreted by the amphids.

Although the mode of action of MhTTL2 is still unknown, MhTTL2 expression is up-regulated in the early-parasitic life stages, and the amphid localization could indicate that it is initially secreted or released from the amphids during infection and it may have a role in the apoplast. Additional experiments looking at fluorescently tagged MhTTL2 with and without the signal peptide would determine its localization in the transgenic plants. The presence of the nematode secretion signal on the effector Mi-CRT was necessary and sufficient to drive secretion of the effector through the plant's own secretion machinery (Jaouannet et al. 2013). If the nematode signal peptide is sufficient for MhTTL2 export, then transgenic plants would produce MhTTL2 targeted to the extracellular space. As an alternative, the nematode effector could be fused to a plant secretion signal peptide to determine if this is sufficient to drive secretion to the apoplast. The transgenic plants with MhTTL2 in the apoplast could then be tested for altered nematode susceptibility. In the future, these tests would shed light on whether MhTTL2 functions in the apoplasm.

Mh265 is a novel root-knot nematode gene whose transcript accumulated in the preparasitic juvenile and in the early stages of parasitism ( $6 \mathrm{dpi}$ ), suggesting that Mh265 could have a role in either penetration, early infection processes, or both. The accumulation of Mh265 transcript in the esophageal gland of the juvenile indicates that $\mathrm{Mh} 265$ is secreted from the stylet into the plant cell. In line with this, we found that Arabidopsis plants expressing Mh265 in the plant cell cytoplasm were more susceptible to both root-knot and cyst nematodes. To determine if the plants ectopically expressing Mh265 had an effect on basal immunity, we treated the transgenic plants with the elicitor flg22 and found that these plants showed suppressed flg22-induced callose deposition compared with the controls. Callose is produced in response to nematode infection (Grundler et al. 1997; Hofmann et al. 2010; Hussey et al. 1992; Waetzig

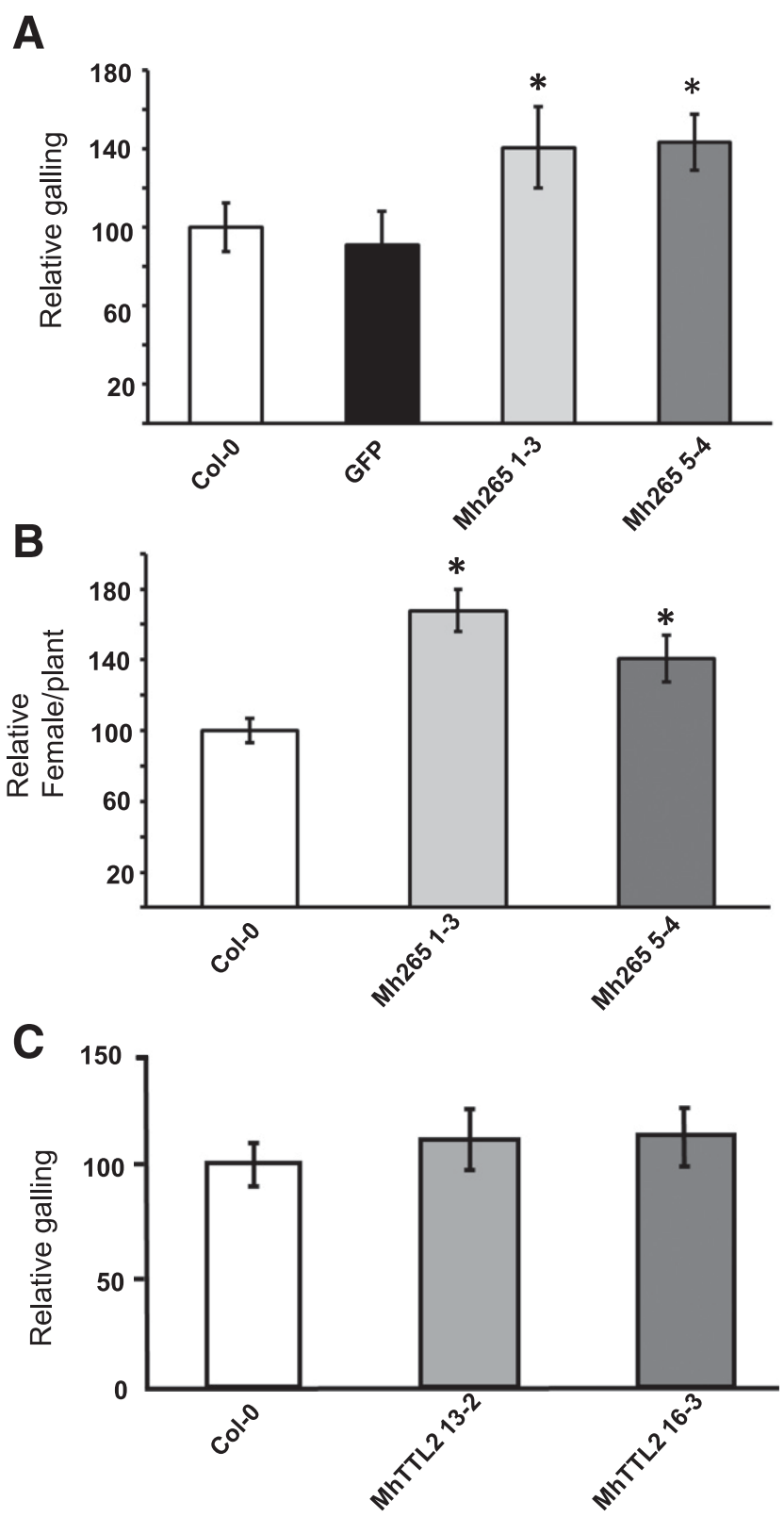

Fig. 6. Transgenic lines expressing Mh265 are more susceptible to Meloidogyne hapla, but lines expressing MhTTL2 are not altered in their nematode susceptibility. A, The relative number of galls in the two lines expressing Mh265 (lines 1-3 and 5-4) was higher than in the controls Col-0 and Col-0 35S::GFP (labeled GFP). Two-week-old seedlings grown on Murashige and Skoog media were inoculated with $100 \mathrm{M}$. hapla, and galling was quantified at 4 weeks postinfection. The average number of galls per plant in Col-0 was set as $100 \%$. Values are the means of at least two independent experiments \pm standard error of the mean (SEM). One asterisk $(*)$ indicates $P<0.005$, using Wilcoxon signed-rank test $(n=88,29,88$, and 104, respectively). B, Transgenic lines expressing Mh265 have more Heterodera schachtii females per plant than the control Col-0 at 12 days postinfection. The average number of females per plant was set to $100 \%$. Values are the means of three independent experiments \pm SEM. One asterisk (*) indicates $P<0.05$, using Student's $t$ test $(n=37,39,30$, respectively). $\mathbf{C}$, The relative number of galls at 4 weeks postinoculation was determined for the transgenic Arabidopsis expressing MhTTL2 (lines 13-2 and 16-3). The average number of galls per plant in Col-0 at 14 days postinoculation was set to $100 \%$. Values are the mean of three experiments \pm SEM, $n=30$. 

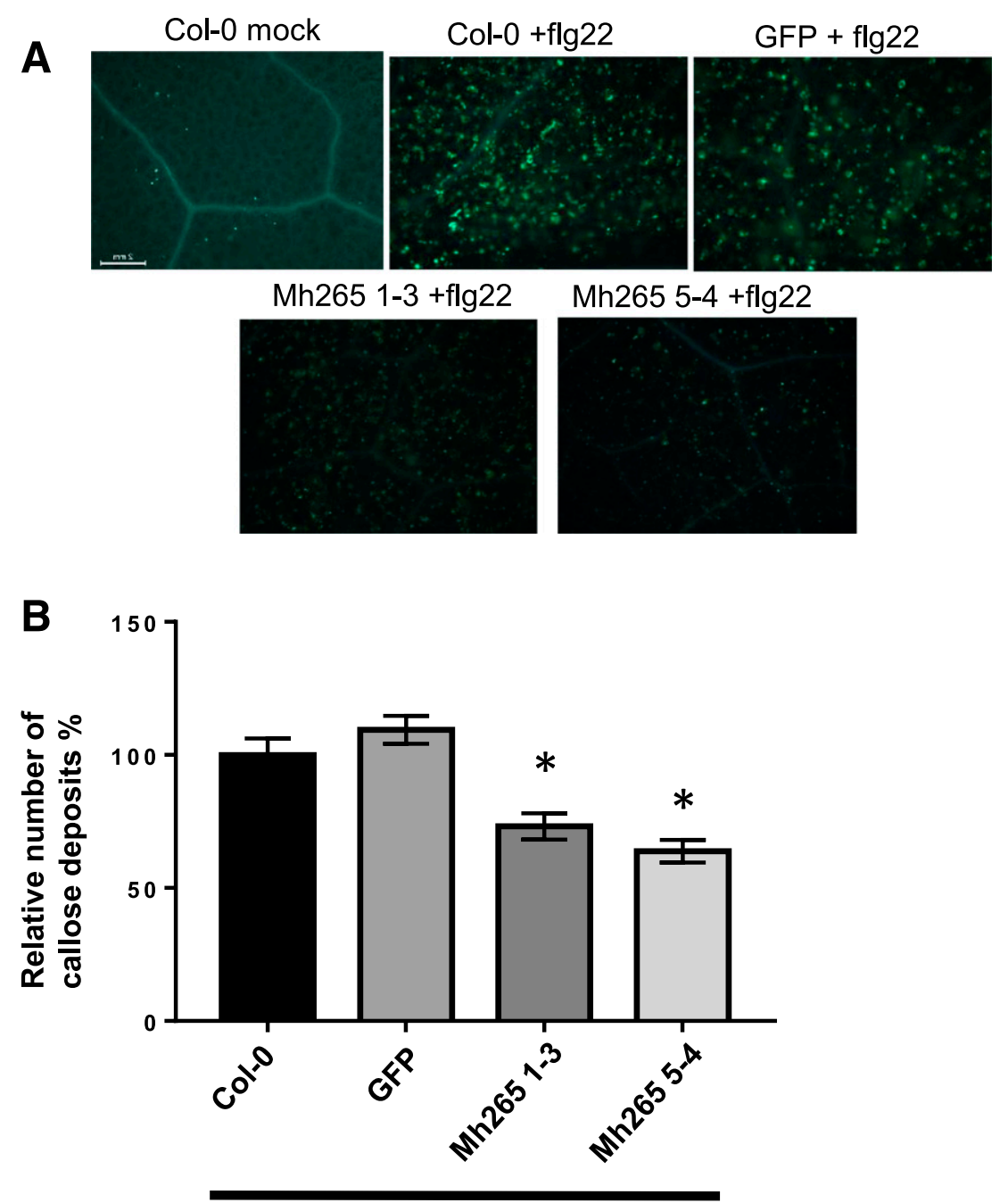

+flg22

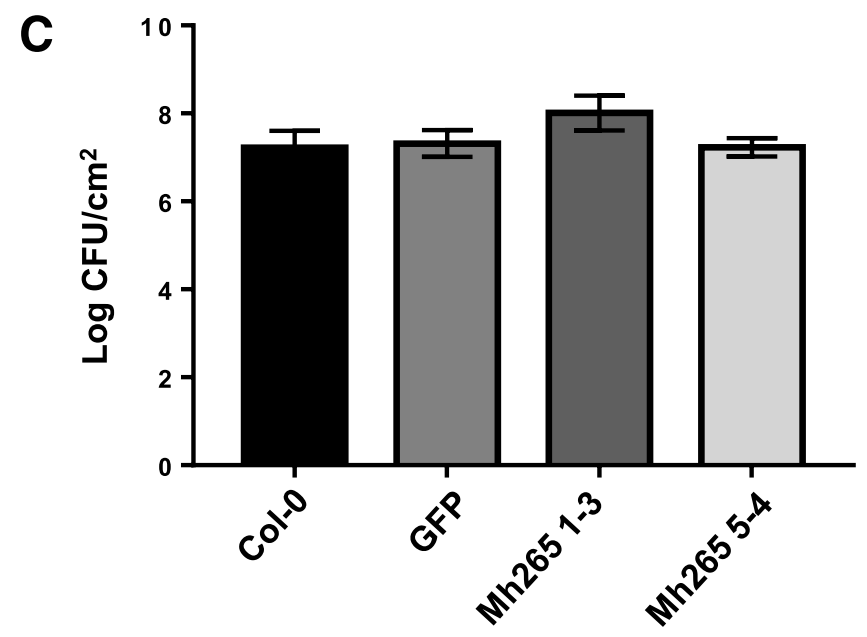

Fig. 7. Mh265 transgenic plants showed suppressed flg22-induced callose deposition but are not altered in Pseudomonas syringae pv. tomato DC3000 susceptibility. A, Representative photos of leaves showing aniline blue-stained callose deposits in Col-0 mock and flg22-treated Col-0, 35S::GFP, and the two lines expressing the Mh265 transgene, Mh265 1-3 and Mh265 5-4. B, The relative number of fluorescent callose deposits was significantly lower in the transgenic plants compared with the controls (Col-0 and 35S::GFP). Numbers are the means \pm standard error of the mean (SEM) calculated from the field of view $\left(1 \mathrm{~cm}^{2}\right)$ from three independent experiments, in which the value in Col- 0 was set to $100 \%$. One asterisk (*) indicates $P<0.001$ using Student's $t$ test. C, Fully expanded leafs of 4-week-old plants were infiltrated with a $P$. syringae pv. tomato DC3000 suspension $($ optical density at $600 \mathrm{~nm}=0.0001)$. Bacteria were extracted from leaf disks at 3 days post infiltration to determine the number of CFU in the plant. Bars present the mean LogCFU per square centimeter from three biological replicates at 3 days postinoculation \pm SEM. Experiment was repeated three times with similar results. 
et al. 1999). It was recently shown that plants that overexpress the ethylene-response transcription factor RAP2.6 from Arabidopsis have enhanced callose deposition and higher expression of defense-related genes, which correlated with enhanced cyst nematode resistance (Ali et al. 2013). Because increased callose deposition can be linked to enhanced nematode resistance, the nematode may be secreting Mh265 to suppress the callose deposition and promote susceptibility to nematodes.

The EDV system has been used by the oomycete community as a screen to characterize newly identified RXLR motifcontaining effectors (Fabro et al. 2011). This heterologous expression system delivers effectors into the plant cell by utilizing the bacteria's own type III secretion system. Using the EDV system, we could demonstrate that Mh265 enhanced bacterial growth on the plant in the majority of the experiments, which suggested that Mh265 has a role suppressing plant immunity against diverse pathogens. However, for MhTTL2, the results from the EDV system were less clear. For example, initial experiments indicated that MhTTL2 could increase bacterial growth on the plant, but this result was not consistent in subsequent experiments (data not shown). We predicted that variability in the system, particularly if the effects on bacterial growth on the plant were subtle, would make the EDV system difficult to use as a rapid screen to identify and rank nematode effector candidates that suppress plant defenses. Despite these drawbacks, we found that we could use the EDV system, not as a screen, but as a tool to further study the effector Mh265 mode of action. Our data showed that Mh265 expression in bacteria Pst-LUX enhanced its virulence on Arabidopsis. Interestingly, the transgenic plants expressing Mh265 were not changed in their susceptibility to $P$. syringae pv. tomato DC3000. The discrepancy we observe between the results from the EDV assay and the transgenic plant assays may be due to the fact that, when Mh265 is expressed in bacteria, it is codelivered with other effectors from $P$. syringae pv. tomato DC3000 and this may positively affect bacterial virulence. Similar discrepancies between the results between the EDV assays and the transgenic plant assays have also been observed for some oomycete RXLR effectors (Fabro et al. 2011). Overall, looking at the data from the Mh265-EDV assay and the data showing that Mh265 expression in plants resulted in a suppression of flg22-induced callose deposition, we conclude that Mh265 likely acts as a PTI suppressor.

\section{MATERIALS AND METHODS}

\section{Nematode cultures.}

Meloidogyne hapla (VW9) was used in all experiments. To collect nematode eggs, roots from infected tomato (Solanum lycopersicum 'Green Zebra') were mixed vigorously in $10 \%$ commercial bleach for $5 \mathrm{~min}$. The eggs were collected on a $25-\mu \mathrm{m}$ sieve and were further surface-sterilized by vigorously shaking them in $10 \%$ bleach for $5 \mathrm{~min}$, followed by three washes with sterile $\mathrm{H}_{2} \mathrm{O}$. The bleach and wash steps were performed twice. After the last wash, the eggs were pelleted by a final centrifugation $(4,000 \mathrm{rpm}$ for $5 \mathrm{~min})$ and were resuspended in $5 \mathrm{ml}$ of water with $0.1 \%$ sodium dodecyl sulfate and $0.2 \%$ plant preservative mixture (Plant Cell Technology). Freshly hatched $\mathbf{J} 2$ were collected as described (Gleason et al. 2008).

Heterodera schachtii Schmidt used in the experiments was reared on white mustard (Sinapis alba L.) 'Albatros' plants grown aseptically on agar containing $0.2 \%$ Knop medium (Sijmons et al. 1991). Mature cysts were collected in funnels and were hatched in $3 \mathrm{mM} \mathrm{ZnCl} 2$ (Sijmons et al. 1991). The hatched preparasitic J2 were collected from funnels for infecting Arabidopsis plants.

\section{Transgenic lines and nematode assays.}

Sequence analysis for MhTTL2 and Mh265 was conducted with the following programs: SignalP 4.1 (Petersen et al. 2011), TMHMM server v. 2.0, NetAcet 1.0 server (Kiemer et al. 2005), GlycoEP (Chauhan et al. 2013), ClustalOmega (Goujon et al. 2010), and ESPript (Robert and Gouet 2014). The sequences of the homologs were obtained by BLAST searches of databases available online, such as WormBase ParaSite (Howe et al. 2016) and the National Center for Biotechnology Information database.

To clone the coding region of MhTTL2 (without the signal peptide sequence), we amplified a product off $M$. hapla J2 cDNA, using Gateway primers MhTTL2F and MhTTL2R, and amplified a product that was $426 \mathrm{bp}$. However, there were two predicted isoforms of MhTTL2 (426 and $465 \mathrm{bp}$ ), suggesting that there are splice variants of MhTTL2. To test the presence and abundance of the MhTTL2 transcript isoforms, we designed a pair of primers (MhTTL2 isoform PCR forward and MhTTL2 isoform PCR reverse) that would produce an 80-bp PCR product fromMhTTL2 (426 bp) or a 120-bp PCR product from MhTTL2a (465 bp). Total RNA was extracted from $M$. hapla eggs, freshly hatched $\mathbf{J} 2$, or Arabidopsis Col-0 roots inoculated by M. hapla $\mathbf{J} 2$ at 6 dpi, using RNeasy mini kit (Qiagen). Total RNA was treated with DNase I (Thermo Scientific) and cDNA was synthesized using OligodT primer with Superscript III reverse transcription mix (Invitrogen). The cDNA was used as template to amplify MhTTL2 transcript isoforms using MhTTL2 isoform PCR forward and MhTTL2 isoform PCR reverse primers with New England Biolabs Taq DNA polymerase. PCR condition and cycles were denature at $95^{\circ} \mathrm{C}$ for $2 \mathrm{~min}$, followed by 40 cycles of $95^{\circ} \mathrm{C}$ for $20 \mathrm{~s}, 55^{\circ} \mathrm{C}$ for $20 \mathrm{~s}$, and $68^{\circ} \mathrm{C}$ for $20 \mathrm{~s}$. PCR products were detected on $2 \%$ agarose gel.

The open reading frames of Mh265 (minus the predicted signal peptides sequence) and of the GFP were cloned into the binary Gateway overexpression vector $\mathrm{pB} 2 \mathrm{GW} 7$. The construct was transferred to Agrobacterium tumefaciens GV3101 was and transformed into Arabidopsis thaliana Col-0 (N1093),



Fig. 8. Mh265 enhanced the growth of P. syringae pv. tomato DC3000 expressing the luciferase operon on Arabidopsis. Four-week-old plants were spray-inoculated with a bacterial suspension of Pst-LUX transformed with pEDV6-YFP, pEDV6-ATR13 ${ }^{\text {Emco5}}$, or pEDV6-Mh265. At 3 days postinoculation, bioluminescence (light units per milligram of fresh weight) was measured. Bars show the arithmetic mean of five biological replicates \pm standard error of the mean. One asterisk $(*)$ indicates $P<0.05$, using Student's $t$ test. Each experiment was repeated seven times, with similar results in five of seven experiments. 
using the floral dip method. The seeds of the primary transformants were selected for BASTA resistance (Bayer CropScience). In the T2 generation, two lines segregating 3:1 (BASTA-resistant/BASTA-susceptible) and expressing $M h 265$ or MhTTL2 were grown to homozygous T3 lines. For nematode infection assays, Arabidopsis seeds were surface sterilized in $70 \% \mathrm{EtOH}$ for $10 \mathrm{~min}$, were washed in $95 \% \mathrm{EtOH}$, and were allowed to air dry. Seeds were placed on Murashige and Skoog media (Murashige and Skoog 1962) with 20\% sucrose and were incubated with a 14-h light and 10-h dark cycle in a growth chamber at 22 and $18^{\circ} \mathrm{C}$, respectively, 80 to $100 \mu \mathrm{mol}$ photons $/ \mathrm{m}^{2} / \mathrm{s}$, and $60 \%$ humidity. The 14-day-old seedlings were inoculated with 100 to $200 \mathrm{M}$. hapla. Plants were incubated in a growth chamber with $14 \mathrm{~h}$ of light and $10 \mathrm{~h}$ of dark. Galls per root were counted at 4 weeks postinoculation. To monitor nematode penetration and infections, two-week-old seedlings were each inoculated with $100 \mathrm{M}$. hapla J2. At 6 and 14 dpi, the plants were stained with acid fuchsin. These plants were placed into $50 \%$ commercial bleach solution for $2 \mathrm{~min}$, were rinsed with $\mathrm{H}_{2} \mathrm{O}$, and were then placed into a boiling, acid fuchsin staining solution ( $3.5 \mathrm{~g}$ per 1 liter $\mathrm{H}_{2} \mathrm{O}$ ) for $1 \mathrm{~min}$. The stained plants were rinsed in $\mathrm{H}_{2} \mathrm{O}$ and were observed under a stereomicroscope (Leica Microsystems). The cyst nematode infections (Heterodera schachtii) were performed as described before (Siddique et al. 2014). Briefly, seeds were plated for 10 days on $0.2 \%$ Knop medium. Plants were inoculated with 60 to $70 \mathrm{~J} 2$ nematodes per plant. The number of female nematodes per plant was counted at 12 days after infection. Each experiment contained 12 plants per line.

\section{qRT-PCR.}

Total RNA was extracted from eggs, freshly hatched J2, and gall-enriched tissue from infected Arabidopsis roots collected at 6 and 14 dpi. RNA was extracted via the TRIZOL method (Chomczynski 1993). Total RNA was treated with DNase I (1 U/ $\mu \mathrm{l})$ (Thermo Scientific) and the DNA-free RNA was used as a template for cDNA synthesis, using OligodT and random monomers in a reaction with reverse transcription (RevertAid $\mathrm{H}$ Minus Reverse transcription; $200 \mathrm{U} / \mu \mathrm{l}$ ) (Thermo Scientific) in a total volume of $20 \mu \mathrm{l}$. The cDNA was diluted 1:20 with $\mathrm{H}_{2} \mathrm{O}$. qRT-PCR was performed with the MyiQ PCR detection system (BioRad) using 100,000× diluted SYBR Green I mix (Cambrex), $10 \mathrm{nM}$ fluorescein (BioRad), 0.25 U BIOTaq DNA polymerase, $1 \times$ NH4-reaction buffer (Bioline), $100 \mu \mathrm{M}$ deoxynucleotide triphosphates (dNTPs), $0.4 \mu \mathrm{M}$ each primer, and $2 \mu \mathrm{l}$ of diluted cDNA. After an initial extension of $95^{\circ} \mathrm{C}$ for $90 \mathrm{~s}$, there were 40 cycles of $95^{\circ} \mathrm{C}$ for $20 \mathrm{~s}, 55^{\circ} \mathrm{C}$ for $20 \mathrm{~s}$, and $72^{\circ} \mathrm{C}$ for $40 \mathrm{~s}$. Calculations were done according to the $2^{-\Delta C T}$ method (Livak and Schmittgen 2001). Each reaction was performed in triplicate and the results represent the mean of two independent biological experiments. Transcript levels were normalized for each sample with the geometric mean of the M. hapla housekeeping genes Mh18S and MhActin (Iberkleid et al. 2013; Vandesompele et al. 2002). For qRT-PCR analysis of transgene expression in the stable transgenic lines, RNA extraction from Arabidopsis and qRT-PCR analysis were performed as described (Fode et al. 2008). Calculations were done according to the $2^{-\triangle C T}$ method. AtUBQ5 served as a reference gene (Kesarwani et al. 2007).

\section{In situ hybridization.}

Using $M$. hapla cDNA as a template, asymmetric PCR was performed in the presence of DIG-labeled dNTPs (Roche) to generate sense and antisense cDNA probes. Freshly hatched J2 were fixed and were probed following the protocol of de Boer et al. (1998). The DIG-labeled probes were detected by incubation with the alkaline phosphatase-conjugated antidigoxigenin antibody
(Roche Molecular Biochemicals) and the alkaline phosphatase substrate. Representative images were collected with a digital camera on a Leica microscope.

\section{Callose deposition assay.}

The leaves of 4-week-old, soil-grown Arabidopsis plants were infiltrated with $1 \mu \mathrm{M}$ flg22 or water (mock), using a needleless syringe. After infiltration for $24 \mathrm{~h}$, the leaves were collected, were fixed in ethanol, and were stained with $0.01 \%$ aniline blue in phosphate-buffered saline overnight. The leaves were viewed under UV light, $1-\mathrm{cm}^{2}$ areas per leaf were digitally photographed, and callose deposition in these areas was quantified with ImageJ (Schneider et al. 2012). At least 12 leaves from four plants were analyzed per experiment, and the experiment was repeated a total of three times.

\section{Subcellular localization of Mh265 and MhTTL2 in tobacco leaf cells \\ by $A$. tumefaciens-mediated transient expression.}

Effector cDNA sequences without the signal peptide coding region were cloned into the multiple cloning site of the pGUSENTR-3 vector (Zhang et al. 2015), using EcoRI and BamHI restriction sites. This modified entry vector was designed to fuse a GUS reporter gene to the cloned gene (Zhang et al. 2015). The resulting plasmids contained the $M$. hapla effector genes fused with the GUS gene, flanked by attL1 and attL2 sequences. An LR reaction was then performed to clone the GUS-effector fusion into the eGFP fusion binary vector $\mathrm{pSITE}$ 2CA (Chakrabarty et al. 2007) to generate the EGFP-GUSeffector fusions. As a control, the coding region of the eGFP was cloned into the Gateway destination vector pB2GW7 (Karimi et al. 2002). Effector fusion constructs were introduced into A. tumefaciens GV3101 using the freeze-thaw method (Weigel and Glazebrook 2006). Agrobacteria were suspended, at an optical density at $600 \mathrm{~nm}\left(\mathrm{OD}_{600}\right)$ of 0.6 , in infiltration buffer $\left(10 \mathrm{mM} \mathrm{MgCl}_{2}, 10 \mathrm{mM}\right.$ 2-(N-morpholino) ethanesulphonic acid, $\mathrm{pH} 5.6,150 \mu \mathrm{M}$ acetosyringone) and were infiltrated into the leaves of 4-week-old Nicotiana benthamiana plants (Sparkes et al. 2006). In order to ensure the expression of fusion constructs, HcPro, the suppressor of posttranscriptional gene silencing of Potato virus $Y$ (Brigneti et al. 1998), was coinfiltrated with fusion constructs at a 1:1 ratio. Leaf samples were harvested at $72 \mathrm{~h}$ postinoculation for eGFP detection. The eGFP fluorescence was detected at an excitation wavelength of $488 \mathrm{~nm}$, with emission collected between 510 and $550 \mathrm{~nm}$ on a Leica TCS SP8 confocal microscopy.

\section{$P$. syringae pv. tomato $\mathrm{DC} 3000$ growth assay.}

An overnight culture of $P$. syringae pv. tomato DC3000 was used to inoculate $10 \mathrm{ml}$ of King's B medium containing $50 \mu \mathrm{g}$ of rifampicin per milliliter. The culture was grown at $28^{\circ} \mathrm{C}$, with shaking, until it reached an $\mathrm{OD}_{600}=0.8$. Four-week-old soil grown plants were infiltrated using a needle-less syringe with $P$. syringae pv. tomato $\mathrm{DC} 3000\left(\mathrm{OD}_{600}=0.0001,1 \times 10^{5} \mathrm{CFU}\right.$ $\mathrm{ml}^{-1}$ ) into three leaves per plant. At 3 days after infiltration, three leaf discs (total surface $1.14 \mathrm{~cm}^{2}$ ) were collected from each plant. The three leaf discs were incubated in $400 \mu \mathrm{l}$ of $1 \mathrm{mM} \mathrm{MgCl} 2$ for $1 \mathrm{~h}$. A 1:10 serial dilution series was made. First, $100 \mu \mathrm{l}$ of the bacterial solution was added to $900 \mu \mathrm{l}$ of $1 \mathrm{mM} \mathrm{MgCl} 2$. Then $100 \mu \mathrm{l}$ of the previous dilution was added to $900 \mu \mathrm{l}$ of $1 \mathrm{mM} \mathrm{MgCl}$, and $10 \mu \mathrm{l}$ of each dilution was placed on King's B medium with $50 \mu \mathrm{g}$ of rifampicin and $50 \mu \mathrm{g}$ of kanamycin per milliliter. Colonies were counted after the plates were incubated for 2 days at $28^{\circ} \mathrm{C}$. We counted the dilutions that gave between 10 to 50 colonies. The $\log _{10}$-transformed CFU per square centimeter of leaf surface area was calculated from this data. 


\section{EDV system.}

pEDV6-ATR $13^{\text {Emco5 }}$ and pEDV6-YFP in Pst-LUX were gifts from the lab of J. Parker (Max-Planck Institute for Plant Breeding Research). For pEDV6-Mh265, the Mh265 open reading frame (minus signal sequence) was first cloned into the pENTRY-SD-D-TOPO vector (Invitrogen) and was then recombined into the pEDV6 vector by Gateway LR clonase or LR clonase II enzyme mix (Invitrogen). The pEDV6-Mh265 was introduced into Pst-LUX by electroporation. For the EDV system, overnight cultures of Pst-LUX with pEDV6-YFP, pEDV6$A T R 13^{\text {Emco5 }}$, and pEDV6-Mh265 were used to inoculate $10 \mathrm{ml}$ of King's B medium with the appropriate antibiotics and were grown at $28^{\circ} \mathrm{C}$ with shaking until they reached an $\mathrm{OD}_{600}$ of 0.8 to 1 . The cultures were harvested by centrifugation, were washed, and were diluted in $10 \mathrm{mM} \mathrm{MgCl}_{2}, 0.04 \%$ Silwet $\mathrm{L} 77$, to reach an $\mathrm{OD}_{600}$ of 0.2 . Bacterial suspensions $(2 \mathrm{ml}$ per plant) were sprayed onto the leaves of 4-week-old Col-0 plants. At least five plants per Pst-LUX construct were sprayed in each experiment. The plants were kept under a transparent lid to maintain high humidity and were grown under short-day conditions ( $8 \mathrm{~h}$ of light, $16 \mathrm{~h}$ of dark). At $3 \mathrm{dpi}$, the plants were placed into a dark photo chamber with an ultra-low light CCD camera (Hamamatsu). After $5 \mathrm{~min}$ of incubation in the dark, photos were taken with a 300-s exposure time. The luminescence (light units) per milligram of fresh weight was then calculated for each plant. The experiment was repeated at least seven times.

\section{ACKNOWLEDGMENTS}

We acknowledge the financial support of the Deutsche Forschungsgemeinshaft (grant no.GL729/1-1 to C. Gleason). C. Gleason and F. Polzin are grateful to C. Gatz, V. Lipka, and coworkers at Georg-August-University Gottingen for help and support. We thank J. Parker (Max Planck Institute for Plant Breeding Research, Cologne) for the kind gifts of the Pst-LUX strain, the pEDV6 vector, and pEDV6-ATR13 ${ }^{\text {Emco }}$ and pEDV6-YFP constructs. We acknowledge R. Curtis (Bionemax UK Ltd) for the M. hapla isolate used in the experiments. We would also like to thank A. Schouten for his critical reading of this manuscript. We are grateful to P. Okubara, United States Department of Agriculture Agricultural Research Service, for the phylogenetic analyses.

\section{LITERATURE CITED}

Abad, P., Favery, B., Rosso, M. N., and Castagnone-Sereno, P. 2003. Rootknot nematode parasitism and host response: Molecular basis of a sophisticated interaction. Mol. Plant Pathol. 4:217-224.

Abad, P., Gouzy, J., Aury, J. M., Castagnone-Sereno, P., Danchin, E. G., Deleury, E., Perfus-Barbeoch, L., Anthouard, V., Artiguenave, F., Blok, V. C., Caillaud, M. C., Coutinho, P. M., Dasilva, C., De Luca, F., Deau, F., Esquibet, M., Flutre, T., Goldstone, J. V., Hamamouch, N., Hewezi, T., Jaillon, O., Jubin, C., Leonetti, P., Magliano, M., Maier, T. R., Markov, G. V., McVeigh, P., Pesole, G., Poulain, J., Robinson-Rechavi, M., Sallet, E., Segurens, B., Steinbach, D., Tytgat, T., Ugarte, E., van Ghelder, C., Veronico, P., Baum, T. J., Blaxter, M., Bleve-Zacheo, T., Davis, E. L., Ewbank, J. J., Favery, B., Grenier, E., Henrissat, B., Jones, J. T., Laudet, V., Maule, A. G., Quesneville, H., Rosso, M. N., Schiex, T., Smant, G., Weissenbach, J., and Wincker, P. 2008. Genome sequence of the metazoan plant-parasitic nematode Meloidogyne incognita. Nat. Biotechnol. 26:909-915.

Ali, M. A., Abbas, A., Kreil, D. P., and Bohlmann, H. 2013. Overexpression of the transcription factor RAP2.6 leads to enhanced callose deposition in syncytia and enhanced resistance against the beet cyst nematode Heterodera schachtii in Arabidopsis roots. BMC Plant Biol. 13:47.

Brigneti, G., Voinnet, O., Li, W. X., Ji, L. H., Ding, S. W., and Baulcombe, D. C. 1998. Viral pathogenicity determinants are suppressors of transgene silencing in Nicotiana benthamiana. EMBO J. 17:6739-6746.

Caillaud, M. C., Dubreuil, G., Quentin, M., Perfus-Barbeoch, L., Lecomte, P., de Almeida Engler, J., Abad, P., Rosso, M. N., and Favery, B. 2008. Root-knot nematodes manipulate plant cell functions during a compatible interaction. J. Plant Physiol. 165:104-113.

Chakrabarty, R., Banerjee, R., Chung, S. M., Farman, M., Citovsky, V., Hogenhout, S. A., Tzfira, T., and Goodin, M. 2007. PSITE vectors for stable integration or transient expression of autofluorescent protein fusions in plants: Probing Nicotiana benthamiana-virus interactions. Mol. Plant-Microbe Interact. 20:740-750.

Chauhan, J. S., Rao, A., and Raghava, G. P. 2013. In silico platform for prediction of $\mathrm{N}-, \mathrm{O}$ - and $\mathrm{C}$-glycosites in eukaryotic protein sequences. PLoS One 8:e67008.

Chen, S., Chronis, D., and Wang, X. 2013. The novel GrCEP12 peptide from the plant-parasitic nematode Globodera rostochiensis suppresses flg22-mediated PTI. Plant Signal. Behav. 8:e25359.

Chitwood, D. J. 2003. Research on plant-parasitic nematode biology conducted by the United States Department of Agriculture-Agricultural Research Service. Pest Manag. Sci. 59:748-753.

Chomczynski, P. 1993. A reagent for the single-step simultaneous isolation of RNA, DNA and proteins from cell and tissue samples. Biotechniques 15:532-534, 536-537.

de Almeida Engler, J., and Gheysen, G. 2013. Nematode-induced endoreduplication in plant host cells: Why and how? Mol. PlantMicrobe Interact. 26:17-24.

de Boer, J. M., Yan, Y., Smant, G., Davis, E. L., and Baum, T. J. 1998. Insitu hybridization to messenger RNA in Heterodera glycines. J. Nematol. 30:309-312.

Dodds, P. N., and Rathjen, J. P. 2010. Plant immunity: Towards an integrated view of plant-pathogen interactions. Nat. Rev. Genet. 11:539-548.

Ellinger, D., and Voigt, C. A. 2014. Callose biosynthesis in Arabidopsis with a focus on pathogen response: What we have learned within the last decade. Ann. Bot. (Lond.) 114:1349-1358.

Eves-van den Akker, S., Lilley, C. J., Jones, J. T., and Urwin, P. E. 2014 Identification and characterisation of a hyper-variable apoplastic effector gene family of the potato cyst nematodes. PLoS Pathog. 10:e1004391.

Fabro, G., Steinbrenner, J., Coates, M., Ishaque, N., Baxter, L., Studholme, D. J., Korner, E., Allen, R. L., Piquerez, S. J., Rougon-Cardoso, A., Greenshields, D., Lei, R., Badel, J. L., Caillaud, M. C., Sohn, K. H., Van den Ackerveken, G., Parker, J. E., Beynon, J., and Jones, J. D. 2011. Multiple candidate effectors from the oomycete pathogen Hyaloperonospora arabidopsidis suppress host plant immunity. PLoS Pathog. 7: e1002348.

Fode, B., Siemsen, T., Thurow, C., Weigel, R., and Gatz, C. 2008. The Arabidopsis GRAS protein SCL14 interacts with class II TGA transcription factors and is essential for the activation of stress-inducible promoters. Plant Cell 20:3122-3135.

Fuller, V. L., Lilley, C. J., and Urwin, P. E. 2008. Nematode resistance. New Phytol. 180:27-44.

Furlanetto, C., Cardle, L., Brown, D. J. F., and Jones, J. T. 2005. Analysis of expressed sequence tags from the ectoparasitic nematode Xiphinema index. Nematology 7:95-104.

Gao, B., Allen, R., Maier, T., Davis, E. L., Baum, T. J., and Hussey, R. S. 2003. The parasitome of the phytonematode Heterodera glycines. Mol. Plant-Microbe Interact. 16:720-726.

Gleason, C. A., Liu, Q. L., and Williamson, V. M. 2008. Silencing a candidate nematode effector gene corresponding to the tomato resistance gene $M i-1$ leads to acquisition of virulence. Mol. Plant-Microbe Interact. 21:576-585.

Goujon, M., McWilliam, H., Li, W., Valentin, F., Squizzato, S., Paern, J., and Lopez, R. 2010. A new bioinformatics analysis tools framework at EMBL-EBI. Nucleic Acids Res. 38:W695-W699.

Goverse, A., and Smant, G. 2014. The activation and suppression of plant innate immunity by parasitic nematodes. Annu. Rev. Phytopathol. 52: 243-265.

Grebenok, R. J., Pierson, E., Lambert, G. M., Gong, F. C., Afonso, C. L., Haldeman-Cahill, R., Carrington, J. C., and Galbraith, D. W. 1997. Green-fluorescent protein fusions for efficient characterization of nuclear targeting. Plant J. 11:573-586.

Grundler, F. M. W., Sobczak, M., and Lange, S. 1997. Defence responses of Arabidopsis thaliana during invasion and feeding site induction by the plant-parasitic nematode Heterodera glycines. Physiol. Mol. Plant Pathol. 50:419-429.

Haegeman, A., Mantelin, S., Jones, J. T., and Gheysen, G. 2012. Functional roles of effectors of plant-parasitic nematodes. Gene 492:19-31.

Hewitson, J. P., Harcus, Y. M., Curwen, R. S., Dowle, A. A., Atmadja, A. K., Ashton, P. D., Wilson, A., and Maizels, R. M. 2008. The secretome of the filarial parasite, Brugia malayi: Proteomic profile of adult excretory-secretory products. Mol. Biochem. Parasitol. 160:8-21.

Hofmann, J., Youssef-Banora, M., de Almeida-Engler, J., and Grundler, F. M. 2010. The role of callose deposition along plasmodesmata in nematode feeding sites. Mol. Plant-Microbe Interact. 23:549-557.

Holbein, J., Grundler, F. M., and Siddique, S. 2016. Plant basal resistance to nematodes: An update. J. Exp. Bot. 67:2049-2061.

Howe, K. L., Bolt, B. J., Cain, S., Chan, J., Chen, W. J., Davis, P., Done, J., Down, T., Gao, S., Grove, C., Harris, T. W., Kishore, R., Lee, R., Lomax, J., 
Li, Y., Muller, H. M., Nakamura, C., Nuin, P., Paulini, M., Raciti, D., Schindelman, G., Stanley, E., Tuli, M. A., Van Auken, K., Wang, D., Wang, X., Williams, G., Wright, A., Yook, K., Berriman, M., Kersey, P., Schedl, T., Stein, L., and Sternberg, P. W. 2016. WormBase 2016: Expanding to enable helminth genomic research. Nucleic Acids Res. 44:D774-780.

Hussey, R., Mims, C., and Westcott, S. 1992. Immunocytochemical localization of callose in root cortical-cells parasitized by the ring nematode Criconemella xenoplax. Protoplasma 171:1-6.

Iberkleid, I., Vieira, P., de Almeida Engler, J., Firester, K., Spiegel, Y., and Horowitz, S. B. 2013. Fatty acid-and retinol-binding protein, Mj-FAR-1 induces tomato host susceptibility to root-knot nematodes. PLoS One 8: e64586.

Jacob, J., Vanholme, B., Haegeman, A., and Gheysen, G. 2007. Four transthyretin-like genes of the migratory plant-parasitic nematode Radopholus similis: Members of an extensive nematode-specific family. Gene 402:9-19.

Jaouannet, M., Magliano, M., Arguel, M. J., Gourgues, M., Evangelisti, E., Abad, P., and Rosso, M. N. 2013. The root-knot nematode calreticulin Mi-CRT is a key effector in plant defense suppression. Mol. PlantMicrobe Interact. 26:97-105.

Jaubert, S., Laffaire, J. B., Abad, P., and Rosso, M. N. 2002. A polygalacturonase of animal origin isolated from the root-knot nematode Meloidogyne incognita. FEBS Lett. 522:109-112.

Karimi, M., Inze, D., and Depicker, A. 2002. GATEWAY vectors for Agrobacterium-mediated plant transformation. Trends Plant Sci. 7: 193-195.

Kesarwani, M., Yoo, J., and Dong, X. 2007. Genetic interactions of TGA transcription factors in the regulation of pathogenesis-related genes and disease resistance in Arabidopsis. Plant Physiol. 144:336-346.

Kiemer, L., Bendtsen, J. D., and Blom, N. 2005. NetAcet: Prediction of N-terminal acetylation sites. Bioinformatics 21:1269-1270.

Lin, B., Zhuo, K., Chen, S., Hu, L., Sun, L., Wang, X., Zhang, L. H., and Liao, J. 2016. A novel nematode effector suppresses plant immunity by activating host reactive oxygen species-scavenging system. New Phytol. 209:1159-1173.

Livak, K. J., and Schmittgen, T. D. 2001. Analysis of relative gene expression data using real-time quantitative PCR and the $2^{-\Delta \Delta C T}$. Methods 25:402-408.

Luna, E., Pastor, V., Robert, J., Flors, V., Mauch-Mani, B., and Ton, J. 2011. Callose deposition: A multifaceted plant defense response. Mol. PlantMicrobe Interact. 24:183-193.

Manosalva, P., Manohar, M., von Reuss, S. H., Chen, S., Koch, A., Kaplan, F., Choe, A., Micikas, R. J., Wang, X., Kogel, K. H., Sternberg, P. W., Williamson, V. M., Schroeder, F. C., and Klessig, D. F. 2015. Conserved nematode signalling molecules elicit plant defenses and pathogen resistance. Nat. Commun. 6:7795.

Mbeunkui, F., Scholl, E. H., Opperman, C. H., Goshe, M. B., and Bird, D. M. 2010. Proteomic and bioinformatic analysis of the root-knot nematode Meloidogyne hapla: The basis for plant parasitism. J. Proteome Res. 9:5370-5381.

Mitchum, M. G., Hussey, R. S., Baum, T. J., Wang, X., Elling, A. A., Wubben, M., and Davis, E. L. 2013. Nematode effector proteins: An emerging paradigm of parasitism. New Phytol. 199:879-894.

Monaghan, J., and Zipfel, C. 2012. Plant pattern recognition receptor complexes at the plasma membrane. Curr. Opin. Plant Biol. 15:349-357.

Murashige, T., and Skoog, F. 1962. A revised medium for rapid growth and bioassays with tobacco tissue culture. Physiol. Plant. 15:473-497.

Opperman, C. H., Bird, D. M., Williamson, V. M., Rokhsar, D. S., Burke, M., Cohn, J., Cromer, J., Diener, S., Gajan, J., Graham, S., Houfek, T. D., Liu, Q., Mitros, T., Schaff, J., Schaffer, R., Scholl, E., Sosinski, B. R., Thomas, V. P., and Windham, E. 2008. Sequence and genetic map of Meloidogyne hapla: A compact nematode genome for plant parasitism. Proc. Natl. Acad. Sci. U.S.A. 105:14802-14807.

Perry, R. N. 1996. Chemoreception in plant parasitic nematodes. Annu. Rev. Phytopathol. 34:181-199.

Petersen, T. N., Brunak, S., von Heijne, G., and Nielsen, H. 2011. SignalP 4.0: Discriminating signal peptides from transmembrane regions. Nat. Methods 8:785-786.
Rehman, S., Gupta, V. K., and Goyal, A. K. 2016. Identification and functional analysis of secreted effectors from phytoparasitic nematodes. BMC Microbiol. 16:48.

Robert, X., and Gouet, P. 2014. Deciphering key features in protein structures with the new ENDscript server. Nucleic Acids Res. 42:W320-W324.

Rodiuc, N., Vieira, P., Banora, M. Y., and de Almeida Engler, J. 2014. On the track of transfer cell formation by specialized plant-parasitic nematodes. Front. Plant Sci. 5:160.

Sasser, J. N., and Freckman, D. W. 1987. A world perspective on nematology: The role of society. Pages 7-14 in: Vistas on Nematology: A Commemoration of the Twenty-fifth Anniversary of the Society of Nematologist. Veech, J. A., and Dickson, D. W., eds. Society of Nematologists, Hyattsville, MD, U.S.A.

Saverwyns, H., Visser, A., Van Durme, J., Power, D., Morgado, I., Kennedy, M. W., Knox, D. P., Schymkowitz, J., Rousseau, F., Gevaert, K., Vercruysse, J., Claerebout, E., and Geldhof, P. 2008. Analysis of the transthyretin-like (TTL) gene family in Ostertagia ostertagi-Comparison with other strongylid nematodes and Caenorhabditis elegans. Int. J. Parasitol. 38:1545-1556.

Schneider, C. A., Rasband, W. S., and Eliceiri, K. W. 2012. NIH Image to ImageJ: 25 years of image analysis. Nat. Methods 9:671-675.

Semblat, J. P., Rosso, M. N., Hussey, R. S., Abad, P., and CastagnoneSereno, P. 2001. Molecular cloning of a cDNA encoding an amphidsecreted putative avirulence protein from the root-knot nematode Meloidogyne incognita. Mol. Plant-Microbe Interact. 14:72-79.

Senthil-Kumar, M., and Mysore, K. S. 2013. Nonhost resistance against bacterial pathogens: Retrospectives and prospects. Annu. Rev. Phytopathol. 51:407-427.

Siddique, S., Matera, C., Radakovic, Z. S., Hasan, M. S., Gutbrod, P., Rozanska, E., Sobczak, M., Torres, M. A., and Grundler, F. M. 2014. Parasitic worms stimulate host NADPH oxidases to produce reactive oxygen species that limit plant cell death and promote infection. Sci. Signal. 7:ra33.

Sijmons, P. C., Grundler, F. M. W., Von Mende, N., Burrows, P. R., and Wyss, U. 1991. Arabidopsis thaliana as a new model host for plantparasitic nematodes. Plant J. 1:245-254.

Sohn, K. H., Lei, R., Nemri, A., and Jones, J. D. G. 2007. The downy mildew effector proteins ATR1 and ATR13 promote disease susceptibility in Arabidopsis thaliana. Plant Cell 19:4077-4090.

Sonnhammer, E. L., and Durbin, R. 1997. Analysis of protein domain families in Caenorhabditis elegans. Genomics 46:200-216.

Sparkes, I. A., Runions, J., Kearns, A., and Hawes, C. 2006. Rapid, transient expression of fluorescent fusion proteins in tobacco plants and generation of stably transformed plants. Nat. Protoc. 1:2019-2025.

Teixeira, M. A., Wei, L., and Kaloshian, I. 2016. Root-knot nematodes induce pattern-triggered immunity in Arabidopsis thaliana roots. New Phytol. 211:276-287.

Vandesompele, J., De Preter, K., Pattyn, F., Poppe, B., Van Roy, N., De Paepe, A., and Speleman, F. 2002. Accurate normalization of real-time quantitative RT-PCR data by geometric averaging of multiple internal control genes. Genome Biol. 3:RESEARCH0034.1.

Vieira, P., Danchin, E. G., Neveu, C., Crozat, C., Jaubert, S., Hussey, R. S., Engler, G., Abad, P., de Almeida-Engler, J., Castagnone-Sereno, P., and Rosso, M. N. 2011. The plant apoplasm is an important recipient compartment for nematode secreted proteins. J. Exp. Bot. 62:1241-1253.

Waetzig, G. H., Sobczak, M., and Grundler, F. M. W. 1999. Localization of hydrogen peroxide during the defence response of Arabidopsis thaliana against the plant-parasitic nematode Heterodera glycines. Nematology 1:681-686.

Weigel, D., and Glazebrook, J. 2006. Transformation of agrobacterium using the freeze-thaw method. CSH Protoc. 10.1101/pdb.prot4666. Published online.

Wu, Y., and Zhou, J. M. 2013. Receptor-like kinases in plant innate immunity. J. Integr. Plant Biol. 55:1271-1286.

Zhang, L., Davies, L. J., and Elling, A. A. 2015. A Meloidogyne incognita effector is imported into the nucleus and exhibits transcriptional activation activity in planta. Mol. Plant Pathol. 16:48-60.

Zipfel, C. 2014. Plant pattern-recognition receptors. Trends Immunol. 35: 345-351. 